\title{
Gustatory Interface: The Challenges of 'How' to Stimulate the Sense of Taste
}

\author{
Chi Thanh Vi \\ SCHI Lab, University of Sussex, UK. \\ C.Vi@sussex.ac.uk \\ Daniel Arthur \\ SCHI Lab, University of Sussex, UK. \\ dha23@sussex.ac.uk
}

\author{
Damien Ablart \\ SCHI Lab, University of Sussex, UK. \\ da292@sussex.ac.uk \\ Marianna Obrist \\ SCHI Lab, University of Sussex, UK. \\ M.Obrist@sussex.ac.uk
}

\begin{abstract}
Gustatory interfaces have gained popularity in the field of humancomputer interaction, especially in the context of augmenting gaming and virtual reality experiences, but also in the context of food interaction design enabling the creation of new eating experiences. In this paper, we first review prior works on gustatory interfaces and particularly discuss them based on the use of either a chemical, electrical and/or thermal stimulation approach. We then present two concepts for gustatory interfaces that represent a more traditional delivery approach (using a mouthpiece) versus a novel approach that is based on principles of acoustic levitation (contactless delivery). We discuss the design opportunities around those two concepts in particular to overcome challenges of "how" to stimulate the sense of taste.
\end{abstract}

\section{CCS CONCEPTS}

- Human-centered computing $\rightarrow$ User interface design; Interaction design;

\section{KEYWORDS}

Taste; Taste Experience; Food Interaction Design; Acoustic Levitation; Food Delivery System; Taste Perception

\section{ACM Reference Format:}

Chi Thanh Vi, Damien Ablart, Daniel Arthur, and Marianna Obrist. 2017. Gustatory Interface: The Challenges of 'How' to Stimulate the Sense of Taste. In Proceedings of 2nd ACM SIGCHI International Workshop on Multisensory Approaches to Human-Food Interaction (MHFI'17). ACM, New York, NY, USA, 5 pages. https://doi.org/10.1145/3141788.3141794

\section{INTRODUCTION}

The field of Human-Computer Interaction (HCI) has mainly focused on the use of visual and auditory modalities when designing user interfaces. This has changed through the proliferation of haptic technologies and will in the future be further transformed through the exploration of the sense of smell and taste [24]. The chemical

Permission to make digital or hard copies of all or part of this work for personal or classroom use is granted without fee provided that copies are not made or distributed for profit or commercial advantage and that copies bear this notice and the full citation on the first page. Copyrights for components of this work owned by others than ACM must be honored. Abstracting with credit is permitted. To copy otherwise, or republish, to post on servers or to redistribute to lists, requires prior specific permission and/or a fee. Request permissions from permissions@acm.org.

MHFI'17, November 13, 2017, Glasgow, UK

(c) 2017 Association for Computing Machinery.

ACM ISBN 978-1-4503-5556-8/17/11 . .\$15.00

https://doi.org/10.1145/3141788.3141794 senses are particularly of interest in the context of food-interaction design, linked to the study of food in everyday life (e.g., [3][5]), investigating the ecologies of domestic food consumption [6], product and package design [22], but also with respect to the exploration of novel interaction concepts (e.g., shape-changing food [26], edible screen/interface [2]).

When it comes to the design of food interaction and gustatory interface design, $\mathrm{HCI}$ is still facing various challenges related to the "how" of stimulating the sense of taste. Within HCI, taste stimulation is mainly achieved through the use of chemical stimulation (e.g., solutions for basic tastes [11][14]) or through electrical and/or thermal stimulation of the users' tongue (e.g., [12][18][19]).

A systematic review and discussion of the possibilities and pitfalls around stimulating the chemical senses (taste and smell) was recently presented by Spence et al. [23], providing a solid foundation for future work. Here, we extend the discussion by reviewing the specificities of gustatory interfaces using both chemical and electrical/thermal stimulation approaches. We then move on and introduce two concepts of gustatory interfaces we were actively involved designing and developing. The first concept refers to a device that involves five basic tastes that can be flexibly controlled, and is inspired by LOLLio, a taste-based gaming interface [11]. The second concept presents a new interaction concept for human food interaction exploiting principles of acoustic levitation.

We conclude with a reflection on the emerging design opportunities around the sense of taste and discuss how particularly the two concepts we introduce could provide new approaches in food experience design.

\section{GUSTATORY INTERFACES}

Current gustatory interface developed within the field of HCI can be categorized into two main groups based on their stimulation approach to create a taste sensation on the users' tongue: (1) chemical stimulation, and (2) electrical and/or thermal stimulation. Below we review and classify prior works on gustatory interfaces (see Table 1 below for an overview) based on the following three criteria:

- Materials used in the specific gustatory interface (e.g., cartridges, pumps)

- Interaction method used for the human interaction with the gustatory interface (e.g., passive vs. active)

- Capability of the gustatory interface (e.g., how many tastes can be stimulated, combination of taste stimuli) 
Table 1: Overview on gustatory interfaces in HCI, divided by chemical and electrical/thermal stimulation, clustered along the 3 main criteria

\begin{tabular}{|c|c|c|c|c|}
\hline $\begin{array}{c}\text { Stimulation } \\
\text { Approach }\end{array}$ & $\begin{array}{l}\text { Gustatory } \\
\text { Interface }\end{array}$ & Materials used & Interaction Method & Capabilities \\
\hline \multirow{5}{*}{$\begin{array}{l}\text { Chemical (e.g., } \\
\text { cartridges with } \\
\text { flavouring } \\
\text { agents or basic } \\
\text { tastes) }\end{array}$} & TasteScreen [9] & $\begin{array}{l}\text { A USB device contains } 20 \text { small } \\
\text { plastic flavour cartridges, } \\
\text { mounted on top of the screen. }\end{array}$ & $\begin{array}{l}\text { Users lick the screen to sample } \\
\text { the taste. }\end{array}$ & $\begin{array}{l}\text { Deliver liquid in the } \\
\text { cartridges (e.g., } \\
\text { lemonade, milk, coffee, } \\
\text { wines). }\end{array}$ \\
\hline & $\begin{array}{l}\text { BeanCounter } \\
{[9]}\end{array}$ & $\begin{array}{l}\text { Rods (made from transparent } \\
\text { acrylic), each is filled with a } \\
\text { flavour of jelly beans. } \\
\text { The bottoms of the rods are } \\
\text { sealed with electronically } \\
\text { controlled valves. }\end{array}$ & $\begin{array}{l}\text { Map information with the } \\
\text { colour of jelly beans. } \\
\text { Users can pick up and eat the } \\
\text { jelly beans. }\end{array}$ & $\begin{array}{l}\text { Tastes of jelly beans: } \\
\text { cherry, strawberry, } \\
\text { orange, lemon, } \\
\text { liquorice, grape. }\end{array}$ \\
\hline & LOLLio [11] & $\begin{array}{l}\text { A small spherical handheld } \\
\text { device and a spherical lollipop } \\
\text { with a plastic stick. } \\
\text { Hardware: tiny pump, taste } \\
\text { compound, Arduino. }\end{array}$ & $\begin{array}{l}\text { User tastes the actual lollipop. } \\
\text { Small amounts of a sour liquid } \\
\text { are pumped from the grip to } \\
\text { the outlet of the candy. }\end{array}$ & Sweet and sour. \\
\hline & EdiPulse [7] & $\begin{array}{l}\text { A chocolate printer. A heart } \\
\text { rate monitor device. }\end{array}$ & $\begin{array}{l}\text { A message made of chocolate is } \\
\text { printed based on the user's } \\
\text { heart rate data. } \\
\text { The user is free to taste or } \\
\text { share the printed chocolate. }\end{array}$ & Chocolate. \\
\hline & $\begin{array}{l}\text { Meta Cookies } \\
{[13]}\end{array}$ & $\begin{array}{l}\text { Plain cookies with AR marker } \\
\text { (printed using branding iron). }\end{array}$ & $\begin{array}{l}\text { User select a type of cookie } \\
\text { (chocolate, strawberry, tea, etc.) } \\
\text { and have the scent dispensed } \\
\text { to the nose. }\end{array}$ & $\begin{array}{l}\text { Simulated taste of the } \\
\text { cookie based on the } \\
\text { olfactory scent. }\end{array}$ \\
\hline \multirow{4}{*}{$\begin{array}{l}\text { Electrical } \\
\text { and/or Thermal }\end{array}$} & $\begin{array}{l}\text { Digital Lollipop } \\
\text { [17] }\end{array}$ & $\begin{array}{l}\text { Tongue interface (two } \\
\text { electrodes) Control system } \\
\text { (control and dispense an } \\
\text { electrical current). }\end{array}$ & $\begin{array}{l}\text { User holds the device to the } \\
\text { tips of their tongues. }\end{array}$ & Sour, bitter, salty. \\
\hline & $\begin{array}{l}\text { Augmented } \\
\text { gustation using } \\
\text { electricity [12] }\end{array}$ & $\begin{array}{l}\text { A positive and a negative straw } \\
\text { inserted into two cups of } \\
\text { electrolyte drink. }\end{array}$ & $\begin{array}{l}\text { User drink the solution from } \\
\text { both cups using the two straws. }\end{array}$ & Electric taste. \\
\hline & $\begin{array}{l}\text { Virtual } \\
\text { Lemonade [18] }\end{array}$ & $\begin{array}{l}\text { pH sensor, RGB sensor, LEDs. } \\
\text { Mouth piece with two silver } \\
\text { electrodes. } \\
\text { Control module with Bluetooth } \\
\text { communication. }\end{array}$ & $\begin{array}{l}\text { User select the colour then } \\
\text { have the lemonade taste } \\
\text { electrically simulated. }\end{array}$ & $\begin{array}{l}\text { Sour }(800 \mathrm{~Hz}, 160 \hat{A} t ̧ A \\
\text { current). }\end{array}$ \\
\hline & $\begin{array}{l}\text { Thermal Sweet } \\
\text { Taste Machine } \\
\text { [21] }\end{array}$ & $\begin{array}{l}\text { An electronic controller circuit, } \\
\text { Electrode that connects to the } \\
\text { Peltier, and a software module. }\end{array}$ & $\begin{array}{l}\text { User put the taste strip on the } \\
\text { surface of their tongue to } \\
\text { perceive taste. }\end{array}$ & $\begin{array}{l}\text { Sweet, (possible) bitter, } \\
\text { and (possible) umami }\end{array}$ \\
\hline
\end{tabular}

\section{Chemical Based Stimulation Approaches}

Traditionally, tastes are given to users through a chemical compound, either in a solid or liquid form. Example ingredients for the five basic tastes (sweet, bitter, sour, salty, and umami) are: glucose for sweet, citric acid for sour, caffeine/quinine for bitter, sodium chloride for salt, and monosodium glutamate for umami [14].

This chemical based approach was, for instance, used by MaynesAminzade [9], who delivered the taste in form of jelly beans with different flavours (e.g., cherry, strawberry, lemon, etc.), with potential applications of memory profiling and network monitoring. The author also presented TasteScreen, a set of small transparent plastic cartridges that can be placed on a screen [9]. These cartridges release a flavouring agent if a user lick the screen.

Additionally, Murer et al. [11] presented LOLLio, a taste-based game interface. The taste dispensing mechanism is inspired by daily objects that people put in their mouth, such as a lollipop or a baby milk bottle (in the first prototype). The metaphor of a lollipop is 
then further developed into a working prototype, where users can experience either sweet or sour throughout a gameplay experience depending on how well or bad they are playing. In a similar vein, Ranasinghe et al. [17] designed a device in the form of a lollipop, however used electrical stimulation to create taste simulations, which we discuss further below.

In another attempt, Narumi et al. [13] introduced the concept of MetaCookie, a system that creates customized tastes with the same plain cookie by dispensing an olfactory scent to user's noses. Users can select between different types of cookies (e.g., strawberry, chocolate, tea).

\section{Electrical and/or Thermal Stimulation Approaches}

It has been shown that people can perceive taste qualities without administering a chemical compound on the tongue, by stimulating the tongue papillae using electrical [15] or thermal [4] stimulation. Plattig [15] stimulated the sweet, sour, and bitter tastes in participants by placing a silver wire $(0.4 \mathrm{~mm}$ tip diameter) on the tip of the tongue and a reference electrode on the left wrist of the subject. Cruz and Green [4] showed that a sweet sensation can be created by warming the anterior (front) edge of the tongue, and a sourness and/or saltiness can be evoked by cooling it. Recently, these findings have been harnessed by HCI designers who demonstrated how to design an application with electrical and thermal stimulation of taste.

Ranasinghe et al. [17] designed a lollipop shaped gustatory device that delivers electricity on the users' tongue. Users hold two electrodes on two sides of the tip of their tongue to perceive the simulated taste. Their results show that participants tasted sourness the most (90\%), then saltiness ( $70 \%)$, bitterness ( $50 \%)$, and sweetness (5\%). In a follow up design, Ranasinghe et al. [18][19] integrated this stimulation approach into a bottle that augments the taste sensation by: (1) superimposing virtual colours onto the drink using Light Emitting Diodes (LED) and (2) applying weak and controlled electrical stimulation on the tongue.

Similarly, Amira Samshir et al. [21] presented a concept that can create different tastes by thermal stimulation. Their design includes an electronic controller circuit, electrode that connects to the Peltier, and a software module. Users can perceive tastes that are thermally stimulated by the Peltier attached with a silver strip. This device was shown to create sweet taste in participants.

\section{Opportunities and Challenges}

In summary, each stimulation approach has its advantages and disadvantages. While the chemical approach is less invasive than the electrical and thermal stimulation of the tongue, it has the disadvantage of requiring continuous fresh preparation and refill of taste stimuli. Electrical and thermal stimulation allow for more control and replication of taste stimuli over a long period of time and over distance (e.g., such as in Taste/IP [16] or virtual lemonade [18]). However, the spectrum of potential taste sensations that can be stimulated through this approach are still limited. Hence, in the early stage of using taste as stimulation approach in HCI, chemical stimulation has the advantage of covering the broad range of taste experiences [14].

\section{NEW CONCEPTS OF GUSTATORY INTERFACES}

In this section, we introduce two concepts for gustatory interfaces employing a chemical stimulation approach. Our intention is not to present each concept in detail (specific technical or perceptual abilities) as each idea is worth a dedicated paper in itself. Our intention is to systematically reflect upon those two concepts in the context of the other devices from prior work. Thus, we will highlight how the complete spectrum of all five basic tastes can be covered (concept 1 , we refer to as TasteBud) and how a totally new delivery mechanism can be exploited (concept 2, we refer to as TastyFloats, see [25] for more details).

\section{First Concept: TasteBud}

TasteBud is composed of six bottles of solution (see Figure 1), each contains one basic taste and one with water as neutral solution. The solution is pumped from each bottle using a peristaltic pump at a controllable speed. Out of each bottle is a tube for the taste solution to be transported. The six tubes for six bottles converges into a single tube (or straw), using a mouthpiece, making it convenient for the user to hold in the mouth during the interaction.

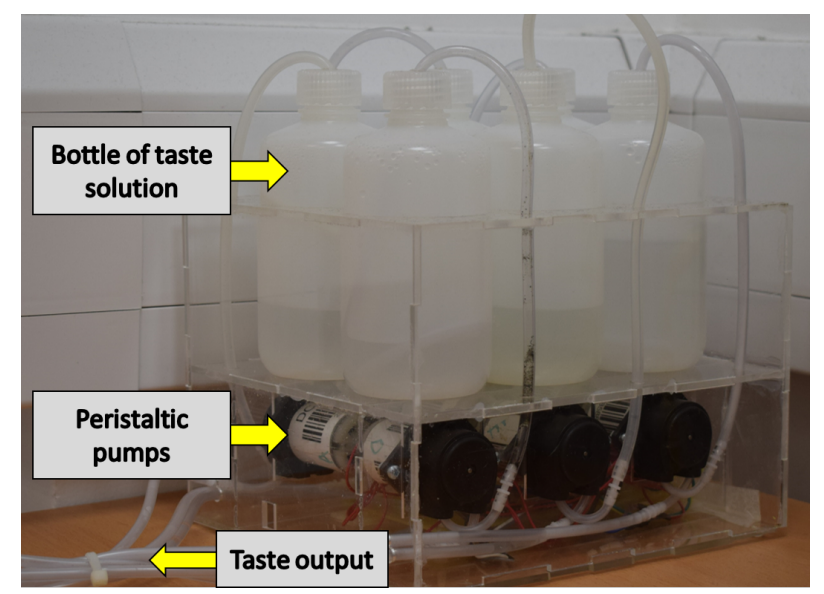

Figure 1: Overview of the TasteBud concept with bottles of taste solutions and six peristaltic pumps controlling delivery of five basic tastes and water.

TasteBud pumps taste solution from one or more bottles into the tubes connecting to participant's mouth. The taste delivery is controlled using an Arduino that allows the delivery of one or multiple tastes at a time, enabling an interactive and flexible gustatory interface. Compared to previous gustatory interfaces, TasteBud, as a standalone unit, offers the capability of delivering single or a combination of multiple taste in one trial. In addition, it offers a plug-and-play interface which allows interactive applications to send control commands to the Arduino board via a serial port to specify the taste delivery (a single or a combination of taste and the amount to deliver). This provides the flexibility and cross-platform ability necessary to stimulate taste in users.

TasteBud can deliver a customizable amount of taste stimuli to the user's mouth whilst they are interacting with the application 
(e.g., playing a game) on a computer connected to the device. The taste stimuli are in a liquid form delivered to the user's mouth. This minimizes the interaction required by hand allowing them to focus on the task at hand. This first concept aims to (a) provide a single taste or a mixture of five basic tastes though a single input device into participant's mouth and (b) can be interactively and flexibly controlled by a computer program. This guarantees a wide design space for potential applications in HCI.

\section{Second Concept: TastyFloats}

TastyFloats is a novel system that uses acoustic levitation to deliver food morsels to the users' tongue (see Figure 2). The technical implementation and first insights into its effect on users' taste perception are described in Vi et al. [25].

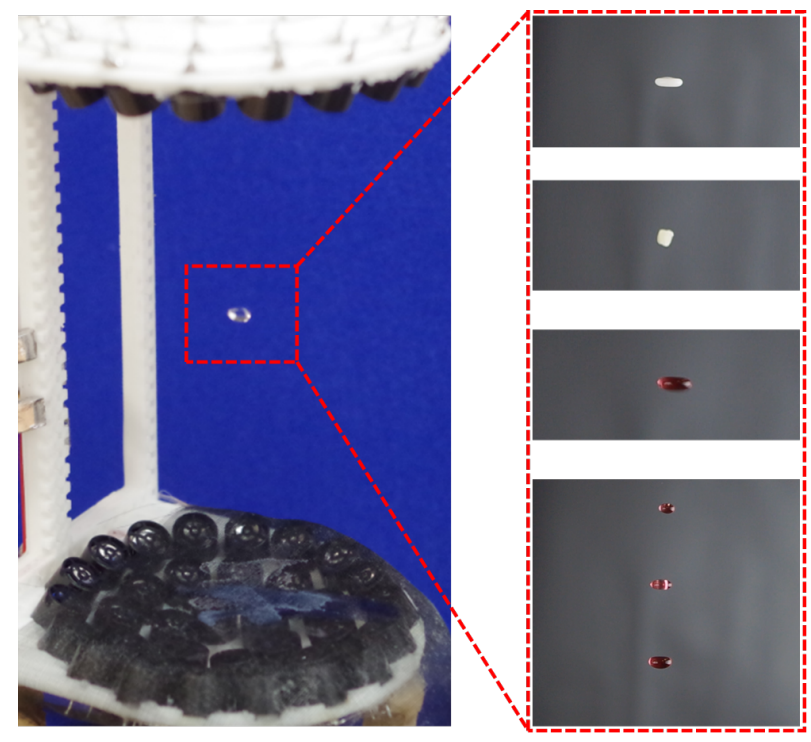

Figure 2: The pick-up unit using acoustic levitation with a drop of water (left) and (right, from top to bottom) milk, cheese, red wine ( 1 drop) and red wine ( 3 drops).

Prior attempts of levitating food have been made by chefs such as Fernando Canales at Etxanobe (Bilbao) [1] and Anthony Martin at Morimoto (New York) [10] who are serving dishes on top of a levitating plate. In these examples, magnetic levitation is used and food is placed on a levitating but static dish where customers have to take the foods using cutlery. TastyFloats is using acoustic levitation that not only allows to levitate the food item itself, but also facilitates a contactless delivery of food into users' mouth without the need for cutlery. Such an approach has been demonstrated in prior attempts to levitate water [8] and salad ingredients [20]. The TastyFloats concept takes those ideas a step further and not just allows static but also dynamic levitation of food items. This type of food delivery has the hygienic advantages as the whole process of food pick-up and delivery is in mid-air. In addition, this mechanism enables rich and interactive user experience by manipulating the combination of food items being levitated and transported into the users' mouth in a pre-defined order (e.g., chefs could specify which food item(s) is released first to user).

\section{DISCUSSION AND DESIGN OPPORTUNITIES}

When using a taste delivery device in an HCI application scenario, one important question is "how" it will affect users taste perception and interaction experience. When using novel technologies, such as acoustic levitation, there are still a lot of unanswered questions on how the size of a stimulus, choice of stimuli (be it a basic taste stimulus or a food item, such as cheese or wine) would influence a users' perception and can ultimately be used in an interaction scenario. Both concepts we presented in this paper, on top of reviewing prior gustatory interface approaches, are using a chemical stimulation approach, covering the whole spectrum of basic taste stimulation. The first concept TasteBud is inspired by LOLLio [11], but extends the previous design by allowing for the stimulation of all five basic tastes. Moreover, TasteBud is designed for a single-user interaction, with one mouthpiece, however, can be extended to multiple users by multiplying the mouthpiece to deliver the same or different tastes to more than one user at time. This system can be integrated into a variety of interactive applications (e.g., notification system, gaming).

The second concept, TastyFloats is a novel approach with high relevance for food interaction design, as it does not only allow the delivery of food morsels (liquid and solid items) from one place to the users' tongue but also opens up new design opportunities for $\mathrm{HCI}$, such as enhance gaming experiences for single and multiple users (see [25] for more discussion on application scenarios). Moreover, TastyFloats has the potential to change user's taste perception and dining experiences. For example, food items being levitated may change their properties (e.g., heating up while transported) due to the continuous induced energy and offer inspiration for chefs, you are interested in creating surprising new food serving experiences. Moreover, chefs can explore new food and flavours combinations (e.g., non-existing menu creations). In summary, our concepts can be used in combination with other senses to enhance user experiences while interacting. However, designers should consider the moment of when to deliver the taste to create an optimal experience. Moreover, different taste have different temporal properties, making the synchronisation crucial [14]. Further research with the sense of taste can explore this cross-sensory integration.

\section{CONCLUSION}

Gustatory interfaces are fascinating and challenging for HCI in general and for food interaction design research in particular. The success of such interfaces depends ultimately from the end user, and if they are willing to accept the stimulus to be delivered into their mouths. In contrast to any other sensory stimulation, the sense of taste is best stimulated inside the human body, in a user's mouth. Hence, the question of "how" to stimulate taste sensations is extremely important to discuss, study, and investigate with respect to the various stimulation approaches and purposes of a stimulation. Only if it is made meaningful and implicitly integrated into an interaction and application, the likelihood that users will accept it and enjoy it, will increase. Here we only started to review existing efforts and directions for gustatory interface designs hoping to inspire future research that will transform we will eat, experience food, and interact with technology in the future. 


\section{ACKNOWLEDGMENTS}

This work has received funding from the European Union's Horizon 2020 research and innovation programme under SenseX grant, agreement number 638605 .

\section{REFERENCES}

[1] Fernando Canales. [n. d.]. ([n. d.]). Retrieved September 21, 2017 from https: //fernandocanales.com/

[2] Edible Cinema. [n. d.]. ([n. d.]). Retrieved September 21, 2017 from http:// ediblecinema.co.uk

[3] Rob Comber, Eva Ganglbauer, Jaz Hee-jeong Choi, Jettie Hoonhout, Yvonne Rogers, Kenton O'Hara, and Julie Maitland. 2012. Food and Interaction Design: Designing for Food in Everyday Life. In CHI '12 Extended Abstracts on Human Factors in Computing Systems (CHI EA '12). ACM, New York, NY, USA, 2767-2770. https://doi.org/10.1145/2212776.2212716

[4] A. Cruz and B. G. Green. 2000. Thermal stimulation of taste. Nature 403, 6772 (Feb 2000), 889-892.

[5] Andrea Grimes and Richard Harper. 2008. Celebratory Technology: New Directions for Food Research in HCI. In Proceedings of the SIGCHI Conference on Human Factors in Computing Systems (CHI '08). ACM, New York, NY, USA, 467476. https://doi.org/10.1145/1357054.1357130

[6] Annika Hupfeld and Tom Rodden. 2012. Laying the Table for HCI: Uncovering Ecologies of Domestic Food Consumption. In Proceedings of the SIGCHI Conference on Human Factors in Computing Systems (CHI '12). ACM, New York, NY, USA, 119-128. https://doi.org/10.1145/2207676.2207694

[7] Rohit Ashok Khot, Ryan Pennings, and Florian 'Floyd' Mueller. 2015. EdiPulse Turning Physical Activity Into Chocolates. In Proceedings of the 33rd Annual ACM Conference Extended Abstracts on Human Factors in Computing Systems (CHI EA '15). ACM, New York, NY, USA, 331-334. https://doi.org/10.1145/2702613.2725436

[8] The Levitron. [n. d.]. ([n. d.]). Retrieved September 21, 2017 from https://goo.gl/ ibNyhs

[9] Dan Maynes-aminzade. 2005. Edible Bits: Seamless Interfaces between People, Data and Food. In Proceedings of the 2005 ACM Conference on Human Factors in Computing Systems (CHI'2005.

[10] Morimoto. [n.d.]. ([n. d.]). Retrieved September 21, 2017 from http://morimotonyc me/

[11] Martin Murer, Ilhan Aslan, and Manfred Tscheligi. 2013. LOLLio: Exploring Taste As Playful Modality. In Proceedings of the 7th International Conference on Tangible, Embedded and Embodied Interaction (TEI '13). ACM, New York, NY, USA, 299-302. https://doi.org/10.1145/2460625.2460675

[12] Hiromi Nakamura and Homei Miyashita. 2011. Augmented Gustation Using Electricity. In Proceedings of the 2Nd Augmented Human International Conference (AH '11). ACM, New York, NY, USA, Article 34, 2 pages. https://doi.org/10.1145/ 1959826.1959860

[13] Takuji Narumi, Takashi Kajinami, Tomohiro Tanikawa, and Michitaka Hirose 2010. Meta Cookie. In ACM SIGGRAPH 2010 Emerging Technologies (SIGGRAPH '10). ACM, New York, NY, USA, Article 18, 1 pages. https://doi.org/10.1145/ 1836821.1836839
[14] Marianna Obrist, Rob Comber, Sriram Subramanian, Betina Piqueras-Fiszman, Carlos Velasco, and Charles Spence. 2014. Temporal, Affective, and Embodied Characteristics of Taste Experiences: A Framework for Design. In Proceedings of the 32Nd Annual ACM Conference on Human Factors in Computing Systems (CHI '14). ACM, New York, NY, USA, 2853-2862. https://doi.org/10.1145/2556288. 2557007

[15] K. H. Plattig and J. Innitzer. 1976. Taste qualities elicited by electric stimulation of single human tongue papillae. Pflügers Archiv 361, 2 (01 Jan 1976), 115-120. https://doi.org/10.1007/BF00583454

[16] Nimesha Ranasinghe, Adrian David Cheok, and Ryohei Nakatsu. 2012. Taste/IP: The Sensation of Taste for Digital Communication. In Proceedings of the 14th ACM International Conference on Multimodal Interaction (ICMI '12). ACM, New York, NY, USA, 409-416. https://doi.org/10.1145/2388676.2388768

[17] Nimesha Ranasinghe and Ellen Yi-Luen Do. 2016. Digital Lollipop: Studying Electrical Stimulation on the Human Tongue to Simulate Taste Sensations. ACM Trans. Multimedia Comput. Commun. Appl. 13, 1, Article 5 (Oct. 2016), 22 pages. https://doi.org/10.1145/2996462

[18] Nimesha Ranasinghe, Pravar Jain, Shienny Karwita, and Ellen Yi-Luen Do. 2017. Virtual Lemonade: Let's Teleport Your Lemonade!. In Proceedings of the Eleventh International Conference on Tangible, Embedded, and Embodied Interaction (TEI '17). ACM, New York, NY, USA, 183-190. https://doi.org/10.1145/3024969.3024977

[19] Nimesha Ranasinghe, Kuan-Yi Lee, Gajan Suthokumar, and Ellen Yi-Luen Do. 2014. Taste+: Digitally Enhancing Taste Sensations of Food and Beverages. In Proceedings of the 22Nd ACM International Conference on Multimedia (MM '14). ACM, New York, NY, USA, 737-738. https://doi.org/10.1145/2647868.2654878

[20] World's First Levitating Food: Heinz Caprese Salad and Acoustic Levitation. [n. d.]. ([n. d.]). Retrieved September 21, 2017 from https://goo.gl/7AMCrC

[21] Nur Amira Samshir, Nurafiqah Johari, Kasun Karunanayaka, and Adrian David Cheok. 2016. Thermal Sweet Taste Machine for Multisensory Internet. In Proceedings of the Fourth International Conference on Human Agent Interaction (HAI '16). ACM, New York, NY, USA, 325-328. https://doi.org/10.1145/2974804. 2980503

[22] G.J.F. Smets and C.J. Overbeeke. 1995. Expressing tastes in packages. Design Studies 16, 3 (1995), 349 - 365. https://doi.org/10.1016/0142-694X(94)00003-V

[23] Charles Spence, Marianna Obrist, Carlos Velasco, and Nimesha Ranasinghe. 2017. Digitizing the chemical senses: Possibilities \& pitfalls. International fournal of Human-Computer Studies 107, Supplement C (2017), 62 - 74. https://doi.org/10. 1016/j.ijhcs.2017.06.003 Multisensory Human-Computer Interaction.

[24] Chi Thanh Vi, Damien Ablart, Elia Gatti, Carlos Velasco, and Marianna Obrist. 2017. Not just seeing, but also feeling art: Mid-air haptic experiences integrated in a multisensory art exhibition. International fournal of Human-Computer Studies 108, Supplement C (2017), 1 - 14. https://doi.org/10.1016/j.ijhcs.2017.06.004

[25] Chi Thanh Vi, Asier Marzo, Damien Ablart, Gianluca Memoli, Sriram Subramanian, Bruce Drinkwater, and Marianna Obrist. 2017. TastyFloats: A Contactless Food Delivery System. In ACM International Conference on Interactive Surfaces and Spaces. ACM, New York, NY, USA, 10. https://doi.org/10.1145/3132272.3134123

[26] Wen Wang, Lining Yao, Teng Zhang, Chin-Yi Cheng, Daniel Levine, and Hiroshi Ishii. 2017. Transformative Appetite: Shape-Changing Food Transforms from 2D to 3D by Water Interaction Through Cooking. In Proceedings of the $2017 \mathrm{CHI}$ Conference on Human Factors in Computing Systems (CHI '17). ACM, New York, NY, USA, 6123-6132. https://doi.org/10.1145/3025453.3026019 